\title{
The Temporal Hyper-Morbidity of Asthma and Attention Deficit Disorder: Implications for Interpretation Based on Comparison of Prospective and Cross-Sectional Population Samples
}

\author{
Pang Hua Chai ${ }^{1}$, Sam Chang $^{2}$, and David Cawthorpe ${ }^{3 凶}$ \\ ${ }^{1}$ Faculty of Kinesiology, The University of Calgary, Calgary, Alberta, Canada \\ ${ }^{2}$ Department of Psychiatry, Cumming School of Medicine, The University of Calgary, Calgary, Alberta, Canada \\ ${ }^{3}$ Departments of Psychiatry and Community Health Sciences, Alberta Children's Hospital Research Institute, Cumming School of Medicine, \\ The University of Calgary, Calgary, Alberta, Canada
}

\begin{abstract}
Objective The purpose of this study was to test the hypothesis that a significant temporal relationship exists between asthma and attention deficit hyperactivity disorder (ADHD).

Methods The population dataset consisted of 95,846,511 physician diagnoses for 768,460 (46\% male) individuals spanning $1993-2010$. Four groups were labeled as having neither Asthma nor ADHD, Asthma only, ADHD only, or both Asthma and ADHD and formed the basis of calculating the odds ratios for each sex describing the association of Asthma and ADHD by age, and, in addition, a prospective sample age (<5 years) between 1993 and 1996 was utilized to evaluate the temporal association between Asthma and ADHD.

Results There was a significant relationship between ADHD and Asthma within the age strata of the sample, one from the cohort and two from the whole sample. When both ADHD and Asthma were diagnosed in the same patients, the age was younger in both cross-sectional and prospective cohort samples. ADHD arose significantly more often after Asthma in the cross-sectional samples stratified on age and in the prospective cohort sample.
\end{abstract}

Conclusion The results are consistent with previous literature where ADHD has been linked to allergic diseases, such as asthma.

Psychiatry Investig 2021;18(2):166-171

Key Words Asthma, Attention deficit hyperactivity disorder, ADHD, Population, Epidemiology, Temporal hyper-morbidity.

\section{INTRODUCTION}

Previous research has indicated that there was no statistical relationship between attention deficit hyperactivity disorder (ADHD) and asthma, arguing against a substantial etiological or pathophysiological relationship between the two conditions. ${ }^{1-4}$ However, other findings have suggested that behavioral disorders, including ADHD, are recurrent in children being treated for asthma. ${ }^{5,6}$

ADHD has been linked to other behavioral disorders and

Received: September 14, 2020 Revised: November 18, 2020

Accepted: December 9, 2020

$\triangle$ Correspondence: David Cawthorpe, $\mathrm{PhD}$

Departments of Psychiatry and Community Health Sciences, Alberta Children's Hospital Research Institute, Cumming School of Medicine, The University of Calgary, 1820 Richmond Rd SW, Calgary T2T 5C7, Alberta, Canada

Tel: +1-403-955-8760, E-mail: cawthord@ucalgary.ca

(c) This is an Open Access article distributed under the terms of the Creative Commons Attribution Non-Commercial License (https://creativecommons.org/licenses/by$\mathrm{nc} / 4.0$ ) which permits unrestricted non-commercial use, distribution, and reproduction in any medium, provided the original work is properly cited. allergic disorders, such as mood orders and asthma.,8 For example, two-thirds of children with ADHD experience co-morbidities. ${ }^{9}$ Furthermore, ADHD symptoms should not be dismissed as part of asthma symptomatology or as a consequence of its treatment. ${ }^{10}$ Additionally, ADHD is associated positively with asthma ${ }^{9}$ and pediatric asthmatic patients have a higher chance to develop ADHD and other behavioral disorders and the severity of asthma symptoms is strongly correlated with the severity of ADHD symptoms. ${ }^{11,12}$ An important common denominator between ADHD and allergic disorders is the probable effect of prenatal stress on both; findings suggest that ADHD children born preterm and/or with mothers who have experienced moderate to acute stress during pregnancy, have a significantly higher chance of acquiring asthma as compared to children born in term and whose mothers were exposed to little stress or no stress at all. ${ }^{13}$ Finally, lifetime prevalence rates of asthma in ADHD patients was $36.6 \%$, compared to a prevalence of $24.3 \%$ in control subjects. In this study, we 
examined the relationship between Asthma and ADHD in a population, with a focus on the temporal association between these two disorders in children similar to other studies,${ }^{14}$ however, without any focus on the influence of other family factors. ${ }^{15-17}$ The hypothesis tested in this report employing two sampling methods for comparison was that there is a significant temporal relationship between Asthma and ADHD.

\section{METHODS}

Data source was Alberta health physician visit and diagnosis data for the Calgary Health Zone in Alberta Canada (Ethics ID: REB15-1057). The data constituted a sixteen-year population dataset consisting of 95,846,511 (36\% male) physician International Classification of Disease (ICD-9) diagnoses and visit dates for 768,460 (46\% male) individuals spanning 19932010. These data served as the basis for constructing the dataset employed in this analysis. All individuals in this dataset (whole sample) were labelled as having neither Asthma nor ADHD (a), Asthma only (b), ADHD only (c) or both Asthma and ADHD (d). These four groups, represented the two by two cell counts (a, b, c, d) of unique individuals, formed the basis of calculating the odds ratios $\{\mathrm{OR}=[(\mathrm{ad}) /(\mathrm{bc})]\}$ for each sex describing the association of Asthma and ADHD within each of the sample frames described below.

From this population dataset, a subset of those under the age of 5 years between 1993 and 1996 was extracted, and these individuals' Asthma and ADHD diagnoses were labelled as being from the prospective cohort within the whole sample from first to last visits up to 2010, with the oldest in December 1995 begin less than 18 years of age in $2010(<18$ years cohort) and the oldest in 1993 begin less than 22 years in 2010 ( $<22$ years cohort). Similarly, other cross-sectional age strata $(<22$ years from the whole sample, and the whole sample) were labelled to examine the effects of sampling frame and age on the relationship between ADHD and asthma in comparison with the prospective cohorts employing odds ratio calculations respective to each sample frame. A separate label was created for the unique individuals in each of the four groups. All diagnoses for these individuals within the large dataset were then labelled in order to link and examine the specific associations between Asthma and ADHD within each group of over time.

Based on the age ( $<5$ years) and time (1993-1996) constraints, it was possible to evaluate the data for a temporal association between Asthma and ADHD in the group with both Asthma and ADHD employing a comparison of proportions where Asthma preceded or followed ADHD, in addition to an overall association employing the odds ratios. For each sample, in the group with both ADHD and Asthma, the data was compared further on the basis of the temporal co-occurrence of the index diagnoses of either Asthma or ADHD, based on the index (first) diagnosis date among those with Asthma and ADHD, two groups were identified with respect to whether or not Asthma arose before or after ADHD. Proportions and $95 \%$ confidence intervals formulated the basis for comparison of the temporal co-occurrence of Asthma and ADHD. Significant statistical differences between proportions in were estimated by comparison of the $95 \%$ confidence intervals using the standard formula, wherein non-overlapping 95\% confidence intervals represent significant differences ( $<<0.05$, with $\mathrm{z}$ set to 1.96$)$.

Therefore, the null hypothesis was constructed on the assumption that, based on chance alone, the respective proportion occurring before or after either disorder would not be significantly different from one another (e.g., non-overlapping $95 \%$ confidence intervals).

\section{RESULTS}

\section{Whole sample}

The sample consisted of 768,460 (46\% male) individuals with a total of $95,846,511$ ( $36 \%$ male) physician-assigned ICD9 diagnoses between April 1993 and April 2010. Males had an average of 97 (SD 130) diagnoses and a range from 1 to 4,343 diagnoses. Females had an average of 148 (SD 155) diagnoses and a range from 1 to 3,558 .

Table 1. Mean minimum age and standard deviation (SD) of index ADHD and Asthma diagnoses by sex

\begin{tabular}{llcc}
\hline \multirow{2}{*}{ Sample } & \multicolumn{1}{c}{ Group } & \multicolumn{2}{c}{ Mean age (SD) } \\
\cline { 3 - 4 } Whole sample & ADHD only & $13(10)$ & $18(15)$ \\
& Asthma only & $26(22)$ & $32(22)$ \\
& Both Asthma and & $6(8)$ & $11(13)$ \\
& ADHD & & \\
Whole sample & ADHD only & $9(6)$ & $11(4)$ \\
$<22$ years & Asthma only & $8(6)$ & $11(6)$ \\
& Both Asthma and & $4(5)$ & $6(5)$ \\
Cohort $<5$ years & ADHD & & \\
$(1993-1996)$ & ADHD only & $3(1)$ & $3(1)$ \\
& Asthma only & $2(1)$ & $2(1)$ \\
& Both ADHD and & $1.7(1)$ & $2(1)$ \\
& Asthma* & & \\
Cohort $<22$ years & ADHD only & $8(3)$ & $9(4)$ \\
& Asthma only & $5(4)$ & $7(5)$ \\
& Both ADHD and & $1.7(1)$ & $2(1)$ \\
& Asthma* & & \\
\hline
\end{tabular}

*same result for Cohort $<5$ years and Cohort $<22$ years. ADHD: attention deficit hyperactivity disorder 


\section{ADHD}

The 28,729 patients with ADHD had a total of $269,936 \mathrm{ADHD}$ diagnoses. Of the ADHD-diagnosed patients there was a perpatient average of $9(\mathrm{SD}=16) \mathrm{ADHD}$ diagnoses and a range from 1 to 464. These ADHD-diagnosed patients had 3,769,393 linked diagnosed disorders/diseases.

\section{Asthma}

Of the 158,064 Asthma-diagnosed patients, there were a total of 971,770 Asthma diagnoses with a per-patient average of $6(\mathrm{SD}=11)$ Asthma diagnoses and a range from 1 to 474 . These Asthma-diagnosed patients had 28,350,854 linked diagnosed disorders/diseases.

\section{Age distributions within samples}

Table 1 indicates that when both ADHD and Asthma are diagnosed in the same patients the age is consistently young-

Table 2. Total frequency of ADHD and Asthma diagnoses by sex by groups

\begin{tabular}{lrrrrr}
\hline \multirow{2}{*}{ Total\# } & \multicolumn{2}{c}{ ADHD } & & \multicolumn{2}{c}{ Asthma } \\
\cline { 2 - 3 } \cline { 5 - 6 } diagnoses by sample & Females & Males & & Females & Males \\
\hline Cohort $<5$ years & 81 & 495 & & 67 & 241 \\
Cohort $<22$ years & 12,586 & 46,399 & & 406 & 2,712 \\
Total $<22$ years & 171,698 & 213,186 & & 57,195 & 184,259 \\
Whole sample & 548,132 & 423,638 & & 70,405 & 199,531 \\
\hline
\end{tabular}

ADHD: attention deficit hyperactivity disorder er in both cross-sectional (Whole Sample and Whole Sample $<22$ years) and prospective (Cohort) samples. Asthma alone is more often diagnosed in the cross-sectional (Whole Sample) on average at an age than $\mathrm{ADHD}$, whereas in the younger cross-sectional (Whole Samples $<22$ years) and prospective (Cohort $<5$ years and Cohort $<22$ years) samples, the diagnosis of Asthma is at a younger age than ADHD.

\section{Frequencies of ADHD and asthma diagnoses within the samples}

Table 2 summarizes the total frequency of diagnoses for each age grouping for cross-sectional and prospective samples for males and females. The frequency of diagnosis increases with age for both cross-sectional and prospective samples for males and females.

\section{Counts of individuals for odds ratios}

Table 3 describes the counts of unique individuals for the whole dataset in each cell employed to calculate the overall odds ratio that includes the other sample groups.

Table 4 presents the sample size $(\mathrm{N})$, mean frequency, standard deviation (SD), minimum (Min.), and maximum (Max.) diagnoses for each category of the under 5 year old cohort.

Table 5 presents the unique individual counts for each age grouping employed in the calculation of odds ratios. Note in Table 5 that the same values arise for both prospective cohort categories as age was constrained to under five years of age

Table 3. Description of unique individuals within groups of whole sample

\begin{tabular}{|c|c|c|c|c|c|}
\hline \multicolumn{2}{|c|}{ Group } & \multirow{2}{*}{$\frac{\text { Cell* }^{*}}{\mathrm{a}}$} & \multirow{2}{*}{$\frac{\text { Female (row \%) }}{320,535(54.1)}$} & \multirow{2}{*}{$\frac{\text { Male (row \%) }}{272,120(45.9)}$} & \multirow{2}{*}{$\frac{\text { Total }}{592,655}$} \\
\hline No Asthma & No ADHD & & & & \\
\hline Asthma & No ADHD & $\mathrm{b}$ & $86,740(59)$ & $60,336(41)$ & 147,076 \\
\hline No Asthma & $\mathrm{ADHD}$ & c & $5,492(31)$ & $12,249(69)$ & 17,741 \\
\hline Asthma & ADHD & d & $3,559(32.4)$ & $7,429(67.6)$ & 10,988 \\
\hline & Total & & $416,326(54.2)$ & $352,134(45.8)$ & 768,460 \\
\hline
\end{tabular}

*a, b, c, d, represent cell values for calculating overall sample odds ratio $(\mathrm{OR})=(\mathrm{ad}) /(\mathrm{bc})$. ADHD: attention deficit hyperactivity disorder

Table 4. Description of unique individuals within categories within the prospective dataset

\begin{tabular}{|c|c|c|c|c|c|}
\hline $\begin{array}{l}\text { Group condition* } \\
\text { (all<18 years) }\end{array}$ & Sex & $\mathrm{N}$ & $\begin{array}{c}\text { Mean diagnoses and } \\
\text { standard deviation }(\mathrm{SD})\end{array}$ & Min. & $\operatorname{Max}$ \\
\hline ADHD-/Asthma- & Female & 110,336 & $46.96(49.61)$ & 1 & 1973 \\
\hline ADHD-/Asthma+ & Female & 2,780 & $104.28(75.39)$ & 1 & 920 \\
\hline ADHD+/Asthma- & Female & 116 & $111.23(68.72)$ & 5 & 381 \\
\hline $\mathrm{ADHD}+/$ Asthma+ & Female & 23 & $171.52(79.73)$ & 60 & 374 \\
\hline ADHD-/Asthma- & Male & 113,655 & $45.4(47.73)$ & 1 & 1567 \\
\hline ADHD-/Asthma+ & Male & 4,426 & $103.81(70.43)$ & 1 & 850 \\
\hline ADHD+/Asthma- & Male & 254 & $123.74(93.34)$ & 3 & 707 \\
\hline ADHD+/Asthma+ & Male & 83 & $174.18(116.09)$ & 17 & 588 \\
\hline
\end{tabular}

*prospective cohort inclusion criteria was <5 years between 1993 and 1996 up to 17 years of age by October 2010. ADHD: attention deficit hyperactivity disorder 
cohort was designed as $<5$ years of age before 1997 (up to the end of 1996), then measured prospectively until 2010. This redundancy serves as an algorithm reliability and validity check.

Table 6 presents for each sample a summary of odds ratios (OR) and their 95\% confidence intervals illustrating the association of ADHD and Asthma. Table 6 shows that there is a significant relationship between ADHD and Asthma in three of the four age groupings, two from the cohort and one from

Table 5. Counts of unique individuals for calculating the odds ratios representing cross-sectional and prospective cohort samples for males and females

\begin{tabular}{lcrrr}
\hline \multicolumn{1}{c}{ Groups } & Cell* & Males & Females & \multicolumn{1}{c}{ Total } \\
\hline Whole sample & & & & \\
Neither & a & 272,120 & 320,535 & 592,655 \\
Asthma & b & 60,336 & 86,740 & 147,076 \\
ADHD & c & 12,249 & 5,492 & 17,741 \\
Both & d & 7,429 & 3,559 & 10,988 \\
& Total & 352,134 & 416,326 & 768,460
\end{tabular}

Whole sample $<22$ years

\begin{tabular}{lcrrr} 
Neither & a & 88,956 & 98,900 & 187,856 \\
Asthma & b & 31,440 & 35,865 & 67,305 \\
ADHD & c & 10,981 & 4,229 & 15,210 \\
Both & d & 7,058 & 2,948 & 10,006 \\
& Total & 138,435 & 141,942 & 280,377 \\
Cohort $<5$ years & & & & \\
Neither & a & 133,672 & 139,023 & 272,695 \\
Asthma & b & 4,426 & 2,780 & 7,206 \\
ADHD & c & 254 & 116 & 370 \\
Both & d & 83 & 23 & 106 \\
& Total & 138,435 & 141,942 & 280,377 \\
Cohort $<22$ years & & & & \\
Neither & a & 133,672 & 139,023 & 272,695 \\
Asthma & b & 4,426 & 2,780 & 7,206 \\
ADHD & c & 254 & 116 & 370 \\
Both & d & 83 & 23 & 106 \\
& Total & 138,435 & 141,942 & 280,377 \\
\hline
\end{tabular}

*a, b, c, d, represent cell values for calculating cohort sample odds ratio $(\mathrm{OR})=(\mathrm{ad}) /(\mathrm{bc})$. ADHD: attention deficit hyperactivity disorder the Whole Sample. Significance is indicated when the lower 95\% confidence intervals are greater than the value one or when the upper $95 \%$ confidence intervals are less than the value one. When $95 \%$ confidence intervals include the value one, the association is not significant at $\mathrm{p}<0.05$. This was the case for the Whole Sample $<22$ years odds ratio.

Table 6 also illustrates the results stemming from the different sampling techniques and outlines the limitations of the method. In terms of drawing inferences about causality, prospective designs are optimal. Note the magnitude of the associations in the two prospective samples are considerably larger than in the cross-sectional samples. In the cross-sectional samples patients can both enter and leave the dataset over time. Whereas, in the prospective sample, individuals can only leave cells, influencing cells 'a' and ' $\mathrm{d}$ ' in the opposite direction. Of course, as entering and leaving is not likely random (e.g., economic migration), both would have an effect proportional to the net count. Leaving cells ' $b$ ' and ' $c$ ' would logically increase the ORs. Similarly, entering cells 'b' and ' $c$ ' would decrease the ORs.

Taken together, the ORs are mostly significantly greater than the value 1, and the range of the $95 \%$ CIs in the Whole Sample under 22 years also have their magnitude mostly $>1$ lending veritas to the association between $\mathrm{ADHD}$ and Asthma, as measured from different sample frames.

\section{Temporal hyper-morbidity of ADHD and asthma}

Table 7 shows the counts of unique individuals with ADHD diagnosed before or after Asthma employed to calculate the

Table 6. Summary of odds ratios (OR) and 95\% confidence intervals $(\mathrm{Cl})$ illustrating the association of ADHD and Asthma within samples

\begin{tabular}{lcc}
\hline \multicolumn{1}{c}{ Sample } & \multicolumn{1}{c}{$\begin{array}{c}\text { OR males } \\
(95 \% \mathrm{CI})\end{array}$} & $\begin{array}{c}\text { OR females } \\
(95 \% \mathrm{CI})\end{array}$ \\
\hline Whole sample & $2.74(1.71,3.77)$ & $2.39(1.35,3.43)$ \\
Whole sample $<22$ years & $1.82(0.79,2.85)$ & $1.92(0.87,2.97)$ \\
Cohort $<5$ years & $9.87(8.59,11.15)$ & $9.92(8.35,11.49)$ \\
Cohort $<22$ years & $9.87(8.59,11.15)$ & $9.92(8.35,11.49)$ \\
\hline
\end{tabular}

${ }^{*} \mathrm{OR}=(\mathrm{ad}) /(\mathrm{bc})$ from corresponding cells $\mathrm{a}, \mathrm{b}, \mathrm{c}$, and $\mathrm{d}$ in Table 5. ADHD: attention deficit hyperactivity disorder

Table 7. Counts of unique individuals by sex where index ADHD was diagnosed in time either before or after the index Asthma diagnosis used to calculate the temporal proportions and their $95 \%$ confidence intervals

\begin{tabular}{|c|c|c|c|c|c|c|}
\hline \multirow{2}{*}{ Sample } & \multicolumn{3}{|c|}{ Males } & \multicolumn{3}{|c|}{ Females } \\
\hline & ADHD $>$ Asthma & ADHD $<$ Asthma & Total & ADHD $>$ Asthma & ADHD $<$ Asthma & Total \\
\hline Cohort $<5$ years & 60 & 22 & 82 & 16 & 7 & 23 \\
\hline Whole sample $<22$ years & 4,637 & 2,410 & 7,047 & 1,763 & 1,178 & 2,941 \\
\hline Whole sample & 4,870 & 2,544 & 7,414 & 2,163 & 1,138 & 3,301 \\
\hline
\end{tabular}

ADHD: attention deficit hyperactivity disorder 
Table 8. Proportions of ADHD within cell 'd' counts that occurred before or after Asthma

\begin{tabular}{llcc}
\hline \multirow{2}{*}{ Sex } & \multicolumn{1}{c}{ Sample } & $\begin{array}{c}\text { Proportion ADHD after Asthma } \\
(95 \% \mathrm{CI})\end{array}$ & $\begin{array}{c}\text { Proportion ADHD before Asthma } \\
(95 \% \mathrm{CI})\end{array}$ \\
\hline Males & Cohort $<5$ years & $0.73(0.72,0.74)$ & $0.27(0.26,0.28)$ \\
& Whole sample $<22$ years & $0.66(0.65,0.67)$ & $0.34(0.33,0.35)$ \\
& Whole sample & $0.66(0.65,0.67)$ & $0.34(0.33,0.35)$ \\
\multirow{2}{*}{ Females } & Cohort $<5$ years & $0.7(0.66,0.73)$ & $0.3(0.27,0.34)$ \\
& Whole sample $<22$ years & $0.6(0.58,0.62)$ & $0.4(0.38,0.42)$ \\
& Whole sample & $0.66(0.64,0.67)$ & $0.34(0.33,0.36)$
\end{tabular}

ADHD: attention deficit hyperactivity disorder

proportions and 95\% confidence intervals for each sample.

The results shown in Table 8 provide an index of the temporal hyper-morbidity of ADHD and Asthma when these two diagnoses arise in the same individual at different times. ADHD arises significantly more often after Asthma in each cross-sectional and prospective sample. The significance of this relationship is given by the non-overlapping 95\% CIs, with the larger proportions indicating the temporal order. Analysis indicated significant difference associated with group membership by gender and age. Males and females with both ADHD and Asthma are significantly different than the other two groups with $\mathrm{ADHD}$ or Asthma alone. This result is supported by the analysis of the age strata represented within and between the aged-based samples (Table 1).

\section{DISCUSSION}

There has been a resurgence of interest in the relationship between Asthma and ADHD in recent years ${ }^{4,18}$ and has identified a need for further investigation. ${ }^{19}$ While small clinical samples have also provided evidence of an association ${ }^{20}$ the study of populations, similar as the present report, has advanced an understanding of the association between Asthma and ADHD. ${ }^{21} \mathrm{~A}$ range of identified factors appear to contribute to the identified association. ${ }^{16}$ As with the range of associated mental and physical disorders, the interaction amongst measured variables and factors in ADHD/Asthma study is complex, ${ }^{22}$ with relatively clear evidence of a genetic association. ${ }^{23}$ Genome-wide cross-trait analysis that identifies shared genetics hold the potential to study causal links between asthma and ADHD, among other mental disorders.

As mentioned in the results section, more individuals were diagnosed with ADHD as compared to asthma. In addition, $\mathrm{ADHD}$ was more prevalent in males and asthma was more prevalent in females. Results also showed that boys and girls with both ADHD and Asthma are significantly different than boys and girls with ADHD or Asthma alone. These results are consistent with previous literature where ADHD has been linked to allergic diseases such as asthma.,

Asthma also occurred significantly more frequently after ADHD for both males and females, with a higher male occurrence as compared to females. These results are novel, as previous literature has suggested that ADHD symptoms could be a part of asthma symptomatology or as a consequence of its treatment ${ }^{10}$ and asthmatic children may have a higher chance to develop ADHD and other behavioral disorders. ${ }^{11}$

In conclusion, more research is needed to further understand the etiological relationship in relationship to the combined risk of ADHD and asthma. More recent research has investigated the effect of the effect of prenatal stress and suggesting that $\mathrm{ADHD}$ children born preterm and/or with mothers who have experienced moderate to acute stress during pregnancy have a significantly higher chance of acquiring asthma. ${ }^{13}$ Research focusing on maternal stress, gestation, and risk for $\mathrm{ADHD}$ and asthma in children ${ }^{15}$ brings forward a novel model and evidence illustrating the importance of examining early childhood comorbidities. To some extent the more sophisticated population studies ${ }^{23}$ provide support of such epigenetic models. The present study establishes the relevance of temporal-hyper-morbidity in any understanding of Asthma and ADHD.

\section{Acknowledgments}

None.

\section{Conflicts of Interest}

The authors have no potential conflicts of interest to disclose.

\section{Author Contributions}

Conceptualization: Pang Hua Chai. Data curation: David Cawthorpe. Formal analysis: Pang Hua Chai, David Cawthorpe. Methodology: David Cawthorpe. Supervision: Sam Chang, David Cawthorpe. Validation: Sam Chang, David Cawthorpe. Project administration: David Cawthorpe. Writing_original draft: Pang Hua Chai. Writing_review \& editing: all authors.

\section{ORCID iDs}

Pang Hua Chai

Sam Chang

https://orcid.org/0000-0002-2886-7437

David Cawthorpe https://orcid.org/0000-0002-9052-1664 


\section{REFERENCES}

1. Biederman J, Milberger S, Faraone SV, Guite J, Warburton R. Associations between childhood asthma and ADHD: issues of psychiatric comorbidity and familiality. J Am Acad Child Adolesc Psychiatry 1994; 33:842-848.

2. Creer TL, Gustafson KE. Psychological problems associated with drug therapy in childhood asthma. J Pediatr 1989;115:850-855.

3. Lenzi F, Cortese S, Harris J, Masi G. Pharmacotherapy of emotional dysregulation in adults with ADHD: a systematic review and meta-analysis. Neurosci Biobehav Rev 2018;84:359-367.

4. Cortese S, Sun S, Zhang J, Sharma E, Chang Z, Kuja-Halkola R, et al. Association between attention deficit hyperactivity disorder and asthma: a systematic review and meta-analysis and a Swedish populationbased study. Lancet Psychiatry 2018;5:717-726.

5. Paul R, Chawarska K, Fowler C, Cicchetti D,Volkmar F. 'Listen my children and you shall hear': auditory preferences in toddlers with autism spectrum disorders. J Speec Lang Hear Res 2007;50:1350-1364.

6. Lindgren S, Lokshin B, Stromquist A, Weinberger M, Nassif E, McCubbin $\mathrm{M}$, et al. Does asthma or treatment with theophylline limit children's academic performance? N Engl J Med 1992;327:926-930.

7. Chen MH, Su TP, Chen YS, Hsu JW, Huang KL, Chang WH, et al. Higher risk of mood disorders among adolescents with ADHD and asthma: a nationwide prospective study. J Affect Disord 2014;156:232-235.

8. Cherkasova M, Sulla EM, Dalena KL, Ponde MP, Hechtman L. Developmental course of attention deficit hyperactivity disorder and its predictors. J Can Acad Child Adolesc Psychiatry 2013;22:47-54.

9. Larson K, Russ SA, Kahn RS, Halfon N. Patterns of comorbidity, functioning, and service use for US children with ADHD, 2007. Pediatrics 2011;127:462-470.

10. Hammerness P, Monuteaux MC, Faraone SV, Gallo L, Murphy H, Biederman J. Reexamining the familial association between asthma and ADHD in girls. J Atten Disord 2005;8:136-143.

11. Blackman JA, Gurka MJ, Gurka KK, Oliver MN. Emotional, developmental and behavioural co-morbidities of children with chronic health conditions. J Paediatr Child Health 2011;47:742-747.

12. Blackman JA, Conaway MR. Developmental, emotional and behavioral co-morbidities across the chronic health condition spectrum. J Pediatr
Rehabil Med 2013;6:63-71.

13. Grizenko N, Fortier ME, Gaudreau-Simard M, Jolicoeur C, Joober R. The Effect of Maternal Stress during Pregnancy on IQ and ADHD Symptomatology. J Can Acad Child Adolesc Psychiatry 2015;24:92-99.

14. Kwon HJ, Lee MY, Ha M, Yoo SJ, Paik KC, Lim JH, et al. The associations between ADHD and asthma in Korean children. BMC Psychiatry 2014;14:70.

15. Tomfohr-Madsen LM, Bayrampour H, Tough S. Maternal history of childhood abuse and risk of asthma and allergy in 2-year-old children. Psychosom Med 2016;78:1031-1042.

16. Liu X, Dalsgaard S, Munk-Olsen T, Li J, Wright RJ, Momen NC. Parental asthma occurrence, exacerbations and risk of attention-deficit/hyperactivity disorder. Brain Behav Immun 2019;82:302-308.

17. van der Schans J, Aikman B, de Vries TW, Hoekstra PJ, Hak E. Association between attention-deficit/hyperactivity disorder and asthma among adults: a case-control study. Chest 2017;151:1406-1407.

18. Mogensen N, Larsson H, Lundholm C, Almqvist C. Association between childhood asthma and ADHD symptoms in adolescence--a prospective population-based twin study. Allergy 2011;66:1224-1230.

19. Cortese S, Sun S, Zhang J, Sharma E, Chang Z, Kuja-Halkola R, et al. Need for further analysis to explore the association between ADHD and asthma-Authors' reply. Lancet Psychiatry 2018;5:963-964.

20. van der Schans J, Cao Q, Bos EH, Rours GIJG, Hoekstra PJ, Hak E, et al. The temporal order of fluctuations in atopic disease symptoms and attention-deficit/hyperactivity disorder symptoms: a time-series study in ADHD patients. Eur Child Adolesc Psychiatry 2020;29:137-144.

21. Chang TH, Tai YH, Dai YX, Chang YT, Chen TJ, Chen MH. Risk of atopic diseases among siblings of patients with attention-deficit hyperactivity disorder: a nationwide population-based cohort study. Int Arch Allergy Immunol 2019;180:37-43.

22. Maitre L, de Bont J, Casas M, Robinson O, Aasvang GM, Agier L, et al. Human Early Life Exposome (HELIX) study: a European populationbased exposome cohort. BMJ Open 2018; 8: e021311.

23. Zhu Z, Zhu X, Liu CL, Shi H, Shen S, Yang Y, et al. Shared genetics of asthma and mental health disorders: a large-scale genome-wide crosstrait analysis. Eur Respir J 2019;54:1901507. 